\title{
ABOUT THE HUMAN RIGHTS UNIT
}


The Human Rights Unit of the Commonwealth Secretariat works to increase awareness of, respect for, and implementation of human rights in the Commonwealth. Declarations by leaders at the biennial Commonwealth Heads of Government meeting provide the mandate for the strategic framework on which the work of the Secretariat's Human Rights Unit is based. These declarations have reaffirmed the commitment of governments to the advancement of fundamental human rights as a core political value of the Commonwealth.

The initiatives and activities of the Human Rights Unit continue to evolve to meet the needs and concerns of the Commonwealth.

The Human Rights Unit's programme activities support the attainment of the Secretariat's strategic goal of strengthening democracy and respect for human rights within the Commonwealth. In order to achieve this, the Human Rights Unit undertakes to:

Advocate for, and support the efforts of member countries to improve adherence to, compliance with, and implementation of international and regional human rights conventions;

Strengthen (or assist in the establishment of) key institutions in member countries that protect and promote human rights, through technical assistance and policy advice;

Promote human rights education and awareness, including through targeted programmes for the uniformed services, government agencies, the judiciary, the media, and universities - with a particular emphasis on young people;

Assist countries, upon their request, to develop coherent and comprehensive national plans of action for the promotion and protection of human rights, in accordance with national priorities;

Develop, publish and promote best practices on human rights across the Commonwealth;

Collaborate with other international actors and participate in the UN human rights system (including the Human Rights Council);

Advise the Commonwealth Secretary-General on issues related to human rights; and

Integrate human rights standards into all Divisions of the Secretariat. 